Fikrinda, W. • I.M.I. Agastya

\title{
Perbaikan keragaan bibit jeruk pamelo tanpa biji dengan strangulasi dan aplikasi beberapa dosis dari dua ZPT BAP dan 2,4-D
}

\section{Improvement of pummelo seedling performance by strangulation and multiple dosage application from two plant growth regulator BAP and 2,4-D}

Diterima : 7 Oktober 2018/Disetujui : 26 Maret 2019 / Dipublikasikan : 31 Maret 2019

CDepartment of Crop Science, Padjadjaran University

\begin{abstract}
Pummelo has prospective to be developed because of its large fruits and fresh taste. The aim of the research was to study the influence of double strangulation and two plant growth regulator to increase vegetative growth and improve performance of Pummelo (Citrus maxima (Brum.) Merr.) seedling. The research was conducted from March to Juli 2018 at plastic house, Laboratory of Agrotechnology, and Laboratory of Biology, Unitri, Malang. Experimental design used completely randomized block design and treatment design was factorial. The first factor was double strangulation with different distance, i.e. $10 \mathrm{~cm}$ and $15 \mathrm{~cm}$, while the second factor was the different dosage and type of growth regulators, i.e. without plant growth regulator, $100 \mathrm{ppm} \mathrm{BAP}, 200 \mathrm{ppm} \mathrm{BAP}$, 2.4-D 100 ppm, and 2.4-D 200 ppm. Strangulation treatment was conducted on April 8 and wire removed on June 3, 2018. The results showed that there were interaction between the location of strangulation and the dose of plant growth regulator on the parameters diameter of stem, number of branches, length of branches, number of leaves, leaf area, and volume of canopy at $1-17$ weeks after treatment (WAT). Furthermore, the result showed double strangulation with distance between the wire 15 $\mathrm{cm}$ had better significant influence on vegetative growth than double strangulation and the distance between the wire $10 \mathrm{~cm}$. Double strangulation and the distance between the wire $15 \mathrm{~cm}$ with BAP $100 \mathrm{ppm}$ treatment was the best treatment on canopy architecture so the light can be used optimally by plant. It was showed by
\end{abstract}

Dikomunikasikan oleh Hidayati Karamina

Fikrinda, W. I.M.I Agastya

Dosen Program Studi Agroteknologi Fakultas Pertanian

Universitas Tribhuwana Tunggadewi

Korespondensi: fikrindawahyu@gmail.com the largest volume of canopy, number of leaf, and leaf area. Besides, the number of branches was the highest if compared to other treatments up to 17 WAT.

Keywords: Canopy architecture - BAP - 2,4-D • Seedless pummelo

Sari Pamelo memiliki prospek yang baik untuk dikembangkan karena buahnya berukuran besar dan memiliki rasa yang segar. Tujuan penelitian ini adalah mempelajari aplikasi strangulasi dan ZPT terbaik dalam merangsang pertumbuhan vegetatif untuk perbaikan keragaan bibit pamelo tanpa biji. Percobaan dilaksanakan pada bulan Maret sampai Juli 2018 di rumah plastik, Laboratorium Agroteknologi, dan Laboratorium Biologi UNITRI, Malang. Rancangan Acak Kelompok (RAK) faktorial dengan dua faktor digunakan pada penelitian ini. Faktor pertama adalah strangulasi ganda dengan jarak antar kawat yang berbeda yaitu $10 \mathrm{~cm}$, dan $15 \mathrm{~cm}$, sedangkan faktor kedua adalah dosis dan jenis zat pengatur tumbuh yang berbeda yaitu tanpa ZPT, BAP 100 ppm, BAP 200 ppm, 2,4-D 100 ppm, dan 2,4-D 400 ppm. Aplikasi strangulasi (pengikatan kawat) dilakukan secara serentak pada bibit pamelo pada April 2018 dan pelepasan kawat dilakukan pada Juni 2018. Berdasarkan analisis ragam yang dilakukan terdapat interaksi antara perlakuan letak strangulasi dengan dosis ZPT pada parameter diameter batang, jumlah tunas, panjang tunas, jumlah daun, luas daun, dan ukuran tajuk pada 1 - 17 minggu setelah perlakuan (MSP). Perlakuan strangulasi ganda $15 \mathrm{~cm}$ dan BAP 100 ppm $\left(\mathrm{j}_{2} \mathrm{~b}_{1}\right)$ merupakan perlakuan terbaik mampu membentuk tajuk terbuka dengan arsitektur kanopi yang baik sehingga cahaya dapat masuk karena memiliki ukuran tajuk yang paling besar, 
jumlah daun, luas daun, serta jumlah tunas yang paling banyak dibandingkan dengan perlakuan lainnya sampai 17 MSP.

Kata kunci: Arsitektur kanopi • BAP • 2,4-D • Pamelo tanpa biji

\section{Pendahuluan}

Pamelo adalah salah satu produk dari komoditas hortikultura yaitu buah-buahan dan memiliki prospek yang baik untuk dikembangkan karena buahnya enak, penampilannya menarik, dan ukurannya besar. Salah satu kultivar yang banyak dibudidayakan di Kudus, Jawa Tengah, adalah Muria Merah 1. Keunggulan buah ini adalah rasanya manis dan buahnya tidak berbiji. Namun demikian, terdapat beberapa kendala dalam produksi buah jenis ini. Diantara beberapa kendala dalam pembibitannya antara lain bentuk cabangnya yang tidak beraturan, cenderung lurus ke atas, bercabang sedikit, dan daunnya terlalu lebar.

Terdapat beberapa teknik budidaya yang dapat merekayasa kendala dari tanaman buah pamelo ini diantaranya adalah strangulasi dan pemberian zat pengatur tumbuh (ZPT). Strangulasi adalah pengikatan batang dengan menggunakan kawat dengan diameter tertentu (disesuaikan dengan umur tanaman) dan pada jangka waktu tertentu untuk menghambat translokasi karbohidrat hasil fotosintesis dari tajuk menuju ke akar. Menurut Susanto et. al., (2002) terhambatnya translokasi karbohidrat ke akar ini akan menyebabkan akar kekurangan karbohidrat sehingga menyebabkan respirasi akar akan menurun dan aktivitas akar dalam mengabsorpsi hara dan mineral menjadi lebih lambat. Pada tanaman yang sudah berbuah, strangulasi dapat digunakan untuk memacu munculnya bunga, pembentukan, dan perkembangan buah, sedangkan pada tanaman belum berbuah dapat digunakan untuk memacu munculnya tunas yang digunakan untuk membentuk tajuk terbuka yang baik pada awal perkembangan tanaman pamelo.

Beberapa zat pengatur tumbuh telah banyak digunakan oleh petani jeruk untuk mengatur pertumbuhan pohon, mengontrol pembungaan dan pembuahan, menstabilkan tingkat produksi, dan meningkatkan kualitas buah. Penelitian Aliyah (2015) menemukan bahwa aplikasi strangulasi dan pinching yang dikombinasikan dengan aplikasi BAP dan $\mathrm{KNO}_{3}$ meningkatkan jumlah cabang, panjang cabang, jumlah daun, luas daun, dan nisbah $\mathrm{C} / \mathrm{N}$ pada bibit pamelo Nambangan. Adapun penelitian Trisna et al., (2013) menunjukkan bahwa pemberian zat pengatur tumbuh Atonik (2,4-D) pada stump jati berpengaruh sangat nyata terhadap pertambahan tinggi dan jumlah daun tanaman. Hingga saat ini penelitian strangulasi pada tanaman muda serta pemberian zat pengatur tumbuh untuk memanipulasi keragaan tanaman jeruk pamelo masih sedikit dilakukan. Pembentukan tunas vegetatif akibat perlakuan strangulasi dan zat pengatur tumbuh pada tanaman muda diharapkan dapat memudahkan pembentukan arsitektur tanaman sejak awal. Pembentukan tajuk tanaman pamelo dari awal dapat meningkatkan produktivitas tanaman ketika tanaman telah masuk dalam fase menghasilkan. Penelitian ini bertujuan untuk mengetahui interaksi antara aplikasi strangulasi dan zat pengatur tumbuh terbaik dalam menghasilkan pertumbuhan vegetatif untuk perbaikan keragaan bibit pamelo.

\section{Bahan dan Metode}

Percobaan dilaksanakan bulan Maret sampai Juli 2018 di rumah plastik, Kelurahan Tunjung Sekar, kecamatan Lowokwaru, Malang. Aplikasi strangulasi (pengikatan kawat) dilakukan secara serentak pada bibit pamelo pada April 2018 dan pelepasan kawat dilakukan pada Juni 2018. Analisis hara dilakukan di Laboratorium Agroteknologi Universitas Tribhuwana Tunggadewi Malang. Analisis brangkasan dilakukan di Laboratorium Biologi, Universitas Tribhuwana Tunggadewi Malang. Bahan yang digunakan dalam penelitian ini adalah 108 bibit pamelo hasil okulasi bersertifikat varietas Muria 1 berumur 6 bulan yang merupakan hasil seleksi (bibit jeruk unggul bermutu bebas penyakit dan memiliki pertumbuhan yang baik). Bibit pamelo diperoleh dari penangkar bibit di Kudus, Jawa Tengah. Bahan yang digunakan untuk perlakuan adalah kawat putih diameter $1 \mathrm{~mm}$. Bahan media tumbuh yang digunakan adalah pasir, tanah, dan pupuk kandang dengan perbandingan volume 2:1:1, kemudian diisikan pada polybag ukuran $35 \mathrm{~cm} x$ $30 \mathrm{~cm}$. Bagian atas media ditambahkan pupuk organik granul dengan bobot $0,5 \mathrm{~kg}$ tiap polybag. Bahan pemeliharaan tanaman yaitu pupuk NPK mutiara 15-15-15 (15 g/L air), pupuk ZA (15 g/L 
air), pupuk gandasil daun, insektisida deltametrin (5 cc/L air) dan paranet $40 \%$ (Sutopo et al., 2005).

Peralatan yang digunakan untuk pembuatan media adalah sekop, cangkul dan timbangan. Peralatan untuk strangulasi yaitu tang untuk mengikat dan melepas kawat, gunting kawat untuk memotong kawat, dan cutter untuk menghilangkan kalus saat pelepasan kawat. Alat untuk pemeliharaan antara lain knapsack sprayer 15 L untuk penyemprotan insektisida, gelas ukur, dan gunting pangkas. Alat untuk pengamatan terdiri dari meteran dan jangka sorong. Percobaan menggunakan Rancangan Acak Lengkap (RAK) dua faktor. Faktor pertama adalah strangulasi ganda dengan jarak antar kawat yang berbeda

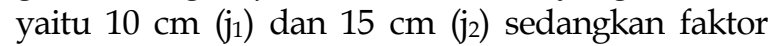
kedua adalah dosis dan jenis zat pengatur tumbuh yang berbeda yaitu tanpa ZPT ( $\left.\mathrm{b}_{0}\right)$, BAP 100 ppm $\left(b_{1}\right)$, BAP 200 ppm $\left(b_{2}\right), 2,4-D 100$ ppm $\left(b_{3}\right)$, 2,4-D 400 ppm $\left(b_{4}\right)$. Percobaan terdiri dari 10 kombinasi perlakuan dan 3 ulangan sehingga terdapat 30 satuan percobaan. Setiap satuan percobaan terdiri dari 2 tanaman sehingga total 60 tanaman.

Pengolahan data dilakukan dengan menggunakan Uji F dan uji lanjut DMRT (Duncan Multiple Range Test) dengan taraf 5\%. Seluruh proses analisis data dilakukan dengan menggunakan perangkat lunak Microsoft $\AA$ Office Excel 2007 dan SAS System for Windows versi 9.13.

Pengamatan dilakukan 1 minggu setelah perlakuan (MSP) atau 7 hari setelah perlakuan strangulasi sampai dua bulan setelah strangulasi dilepas (17 MSP). Parameter pengamatan yang diamati yaitu diameter batang (diukur di atas mata tempel), jumlah tunas dan panjang ratarata tunas per tanaman, jumlah dan luas daun, serta ukuran tajuk.

\section{Hasil dan Pembahasan}

Pengaruh strangulasi tidak menyebabkan kerusakan pada batang bibit pamelo yang ditandai dengan kondisi tanaman pasca strangulasi yang cukup baik. Selama penelitian, tanaman tidak mengalami gangguan abiotik (cekaman air dan cekaman hara) dan gangguan biotik (serangan hama/penyakit) yang menyebabkan kematian tanaman. Suhu di dalam rumah plastik berkisar antara (21 - 34) ${ }^{\circ} \mathrm{C}$ pada pagi sampai sore hari.

Hasil uji $\mathrm{F}$ pada sidik ragam menunjukkan bahwa terdapat interaksi strangulasi dan dosis ZPT terhadap diameter batang, jumlah tunas, panjang tunas, jumlah daun, luas daun dan ukuran tajuk bibit jeruk pamelo pada umur 1 sampai 17 MSP (Tabel 1).

Diameter Batang Atas. Pada 17 MSP, perlakuan strangulasi ganda dengan jarak $15 \mathrm{~cm}$ dan BAP 100 ppm ( $\left.\mathrm{j}_{2} \mathrm{~b}_{1}\right)$ memiliki diameter batang yang paling tinggi namun tidak berbeda dengan perlakuan strangulasi ganda jarak $10 \mathrm{~cm}$ dan 2,4-D $100 \mathrm{ppm}\left(\mathrm{j}_{1} \mathrm{~b}_{3}\right)$ dan perlakuan strangulasi ganda 15 $\mathrm{cm}$ dan 2,4-D 200 ppm (j2 $\mathrm{b}_{4}$ ) (Tabel 1). Diameter tanaman kontrol dengan strangulasi ganda $15 \mathrm{~cm}$ $\left(\mathrm{j}_{2} \mathrm{~b}_{0}\right)$ memiliki diameter yang lebih besar dibandingkan dengan diameter tanaman kontrol dengan strangulasi ganda $10 \mathrm{~cm}\left(\mathrm{j}_{2} \mathrm{~b}_{0}\right)$. Hal ini diduga fotosintat perlakuan kontrol dengan strangulasi ganda $15 \mathrm{~cm}$ lebih banyak digunakan untuk memperbesar diameter batang dibandingkan dengan perlakuan kontrol dengan strangulasi ganda $10 \mathrm{~cm}$. Diduga adanya strangulasi dan pemberian ZPT dapat meningkatkan fotosintat tanaman sehingga memperbesar diameter batang karena fotosintat yang seharusnya mengalir ke akar ditahan oleh kawat strangulasi sampai di batang. Pada tanaman teh belum menghasilkan di dataran rendah, konsentrasi BAP 60 ppm memberikan pengaruh terbaik terhadap diameter batang dan jumlah tunas (Ayuningsari, et al., 2017).

Jumlah Tunas. Strangulasi dan dosis ZPT pada 1 MSP menghasilkan jumlah tunas antara 1 - 2,83 buah tunas. Setelah dilakukan strangulasi, yaitu 9 MSP, terjadi kenaikan jumlah tunas 2 4,83 buah tunas. Pada $9 \mathrm{MSP}$, perlakuan strangulasi ganda $15 \mathrm{~cm}$ dan BAP $100 \mathrm{ppm}$ memiliki jumlah tunas yang paling tinggi yaitu sebesar 4,83 buah namun tidak berbeda dengan perlakuan strangulasi ganda jarak $10 \mathrm{~cm}$ dan BAP 200 ppm $\left(j_{1} b_{2}\right)$ dan strangulasi ganda jarak $10 \mathrm{~cm}$ dan 2,4-D 200 ppm. Namun pada akhir pengamatan yaitu pada $17 \mathrm{MSP}$, perlakuan strangulasi ganda $15 \mathrm{~cm}$ dengan BAP 100 ppm menghasilkan jumlah tunas paling tinggi yaitu sebesar 7,83 buah dan berbeda dengan perlakuan lainnya.

Sostenes (1996) membuktikan bahwa pemberian zat pemecah dormansi BAP dengan dosis 100 ppm yang diaplikasikan tiga bulan setelah pemberian paclobutrazol pada tanaman jeruk (Citrus reticulata) berpengaruh dalam meningkatkan jumlah tunas, panjang tunas tanaman, dan jumlah daun dewasa dibandingkan dengan kontrol. Selanjutnya Sostenes (1996) membuktikan perlakuan BAP dapat meningkatkan jumlah tunas hingga $100 \%$ pada tanaman jeruk siem (C. reticulata Blanco). Penelitian Aliyah (2015) menemukan bahwa 
aplikasi strangulasi dan pinching meningkatkan jumlah cabang, panjang cabang, jumlah daun, luas daun, dan nisbah $\mathrm{C} / \mathrm{N}$ pada bibit pamelo Nambangan.

Panjang Tunas. Berdasarkan Tabel 1, pada 17 MSP tunas terpanjang terdapat pada perlakuan strangulasi ganda $15 \mathrm{~cm}$ dan BAP $100 \mathrm{ppm}\left(\mathrm{j}_{2} \mathrm{~b}_{1}\right)$ namun tidak berbeda dengan perlakuan strangulasi $15 \mathrm{~cm}$ dan 2,4-D $100 \mathrm{ppm}\left(\mathrm{j}_{1} \mathrm{~b}_{3}\right)$. Sedangkan perlakuan dengan tunas terpendek terdapat pada perlakuan kontrol dengan

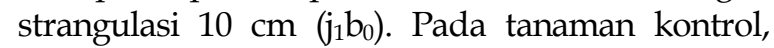
dominansi ujung tetap berjalan dan berdampak pada jumlah tunas yang lebih sedikit sehingga menyebabkan nilai panjang rata-rata tunasnya tinggi. Weaver (1972) menyatakan pengaruh BAP terhadap pemecahan dormansi tunas disebabkan oleh fungsinya dalam mendorong pembelahan sel, sehingga terjadi pemanjangan tunas.

Jumlah Daun. Berdasarkan Tabel 1, pada akhir pengamatan yaitu pada 17 MSP, perlakuan strangulasi ganda $10 \mathrm{~cm}$ dengan BAP $200 \mathrm{ppm}$ $\left(\mathrm{j}_{1} \mathrm{~b}_{2}\right)$ menghasilkan jumlah daun terbanyak namun tidak berbeda dengan perlakuan strangulasi ganda $15 \mathrm{~cm}$ dengan BAP $100 \mathrm{ppm}\left(\mathrm{j}_{2} \mathrm{~b}_{1}\right)$. Jumlah daun ini juga sebanding dengan jumlah tunas yang dihasilkan.

Perlakuan yang memiliki jumlah tunas yang banyak juga menghasilkan jumlah daun yang lebih banyak dibandingkan dengan perlakuan lainnya. Sedangkan perlakuan yang memiliki jumlah tunas yang lebih sedikit memiliki jumlah daun yang sedikit dibandingkan dengan perlakuan lainnya. Hal ini terlihat seperti pada perlakuan kontrol dengan strangulasi $10 \mathrm{~cm}\left(\mathrm{j}_{1} \mathrm{~b}_{0}\right)$ maupun perlakuan kontrol dengan strangulasi 15 $\mathrm{cm}\left(\mathrm{j}_{2} \mathrm{~b}_{0}\right)$. Hasil penelitian ini berbeda dengan penelitian Putri, et. al., (2017) bahwa pada tanaman kamboja jepang pemberian BAP dengan konsentrasi 150 ppm dan 200 ppm menghasilkan rata-rata pertumbuhan lebih tinggi yang dicirikan dari jumlah daun, tinggi tanaman dan tunas lateral.

Luas Daun. Berdasarkan Tabel 1, Pada 17 MSP, perlakuan strangulasi ganda $15 \mathrm{~cm}$ dan BAP $100 \mathrm{ppm}\left(\mathrm{j}_{2} \mathrm{~b}_{1}\right)$ menghasilkan luas daun yang paling besar dan berbeda dengan perlakuan lainnya. Perlakuan kontrol dengan strangulasi 10 $\mathrm{cm}$ menghasilkan luas daun yang paling rendah. Hal ini berkaitan dengan jumlah daun yang diperoleh setiap perlakuan. Perlakuan dengan jumlah daun yang banyak maka akan menghasilkan luas daun yang besar pula. Menurut Paramita, et. al., (2014), konsentrasi ZPT yang terlalu tinggi dapat menghambat pertumbuhan sementara konsentrasi yang terlalu rendah juga tidak akan berpengaruh terhadap pertumbuhan tanaman.

Ukuran Tajuk. Pada 17 MSP, berdasarkan Tabel 1, ukuran tajuk terbesar terdapat pada perlakuan strangulasi ganda $15 \mathrm{~cm}$ dengan BAP $100 \mathrm{ppm}$ dan tidak berbeda dengan perlakuan strangulasi ganda $10 \mathrm{~cm}$ dengan 2,4-D $100 \mathrm{ppm}$. Sedangkan perlakuan dengan ukuran tajuk terendah terdapat pada perlakuan kontrol dengan strangulasi ganda $10 \mathrm{~cm}$. Perlakuan strangulasi ganda $15 \mathrm{~cm}$ membentuk tajuk terbuka dengan arsitektur kanopi yang baik sehingga tanaman tidak terlalu rimbun dan cahaya dapat masuk ke bagian dalam tajuk bibit jeruk. Penelitian ini sejalan dengan penelitian Fikrinda dan Susanto (2017) bahwa perlakuan strangulasi ganda dengan jarak $15 \mathrm{~cm}$ menghasilkan volume tajuk terbesar dengan ciri visual yaitu memiliki tajuk terbuka. Menurut Verheij dan Coronel (1992), pembentukan arsitektur kanopi yang baik dapat meningkatkan efisiensi pemanenan energi matahari, mengendalikan pertumbuhan dan perkembangan tanaman.

\section{Kesimpulan}

Terdapat interaksi antara perlakuan letak strangulasi dengan dosis ZPT pada parameter diameter batang, jumlah tunas, panjang tunas, jumlah daun, luas daun, dan ukuran tajuk pada 1 17 MSP. Perlakuan strangulasi ganda $15 \mathrm{~cm}$ dan BAP 100 ppm ( $\left.\mathrm{j}_{2} \mathrm{~b}_{1}\right)$ merupakan perlakuan terbaik yang mampu membentuk tajuk terbuka dengan arsitektur kanopi yang baik sehingga cahaya dapat masuk karena memiliki ukuran tajuk yang paling besar, jumlah daun, luas daun, serta jumlah tunas yang paling banyak dibandingkan dengan perlakuan lainnya sampai 17 MSP.

\section{Ucapan Terima Kasih}

Ucapan terimakasih ditujukan kepada Kemenristek Dikti Tahun 2018 yang telah memberikan dana penelitian kepada Wahyu Fikrinda, SP, M.Si dalam Penelitian Dosen Pemula Tahun 2017. Selain itu ucapan terima kasih juga diberikan kepada semua pihak yang telah membantu penelitian ini terlaksana dengan baik. 


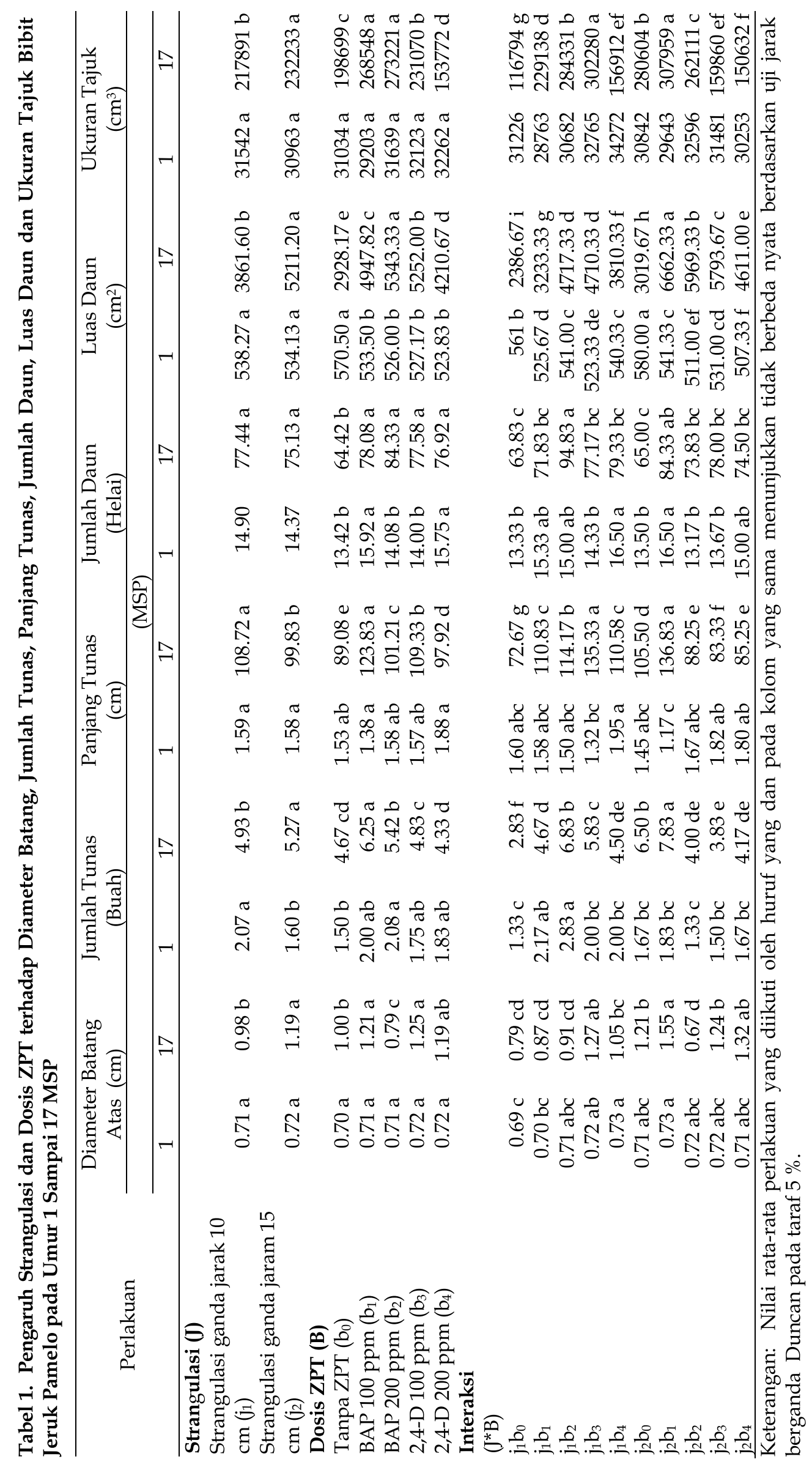




\section{Daftar Pustaka}

Aliyah, M., Susanto, S., Sukma, D., Ardie, S.W. 2015. Performance improvement of young pummelo citrus (Citrus maxima (Burm.) Merr.) by strangulation application and pinching. Asian J. Agric. Res. 9(2): 77-83.

Ayuningsari, I., Rosniawaty, S., Maxiselly, Y., Anjarsari, I.R.D. 2017. Pengaruh konsentrasi benzyl amino purine terhadap pertumbuhan beberapa klon tanaman teh (Camellia sinensis L.) O. Kuntze) belum menghasilkan di dataran rendah. Jurnal Kultivasi. 16(2): 356-361.

Fikrinda, W. dan Susanto, S. 2017. Perbaikan keragaan bibit jeruk pamelo "Nambangan" dengan strangulasi. J. Hortikultura Indonesia. Vol. 8(1) pp 58-66.

Paramita, G., Indradewa, D., Waluyo, S. 2014. Pertumbuhan bibit tujuh klon teh (Camellia sinensis (L.) Kuntze) PGL dengan pemberian bahan mengandung hormon tumbuh alami. Vegetalika 3 (2) : 1-12.

Putri, I.E., Suradinata, Y.R., Kusmiyanti. 2017. Pengaruh pemberian berbagai konsentrasi benzyl amino purine (BAP) terhadap pertumbuhan tiga kultivar tanaman kamboja jepang (Adenium arabicum). Jurnal Kultivasi. 16(1): 305-312.

Sostenes. 1996. Pangaruh waktu pemberian beberapa zat pemecah dormansi yang diaplikasi setelah pemberian paclobutrazol terhadap pertumbuhan dan pembungaan jeruk keprok siem (Citrus retuculata B) [tesis]. Bogor (ID): Institut Pertanian Bogor.

Susanto, S., Minten, S., Mursyada, A. 2002. Pengaruh strangulasi terhadap pembungaan jeruk besar (Citrus grandis (L.) Osbeck) kultivar Nambangan. J. Agrotropika 7(1):57-63.

Sutopo, A. Supriyanto, A. Sugiyatno. 2005. Penetapan Nilai Standar Hara Makro pada Daun untuk Rekomendasi Pemupukan pada Tanaman Pamelo. Prosiding Seminar Nasional Jeruk Tropika Indonesia. 235-241.

Trisna, N., Umar, H., Irmasari. 2013. Pengaruh berbagai jenis zat pengatur tumbuh terhadap pertumbuhan stump jati (Tectona grandis L.F). Jurnal Warta Rimba. 1(1):1-9.

Verheij, E. W. M., Coronel, R. E. 1992. Sumber Daya Nabati Asia Tenggara 2. Gramedia Pustaka Utama. Jakarta.

Weaver, R.D. 1972. Plants Growth Substances in Agriculture. San Fransisco. Freman. 